\title{
Device success and 30-day clinical outcome in patients undergoing preimplant valvuloplasty in transfemoral versus omitting valvuloplasty in transapical transcatheter aortic valve replacement
}

\author{
S. Chiu Wong, MD, ${ }^{a}$ Sumeet Pawar, MD, ${ }^{a}$ Robert M. Minutello, MD, ${ }^{a}$ Evelyn M. Horn, MD, ${ }^{a}$ \\ Nikolaos J. Skubas, MD, FASE, DSc, ${ }^{b}$ Richard B. Devereux, MD, ${ }^{a}$ and Arash Salemi, MD
}

\begin{abstract}
Objectives: The study objective was to evaluate the impact of preimplantation balloon valvuloplasty on procedural outcomes in high-risk or no-option patients with aortic stenosis undergoing Edwards Lifesciences (Irvine, Calif) Sapien valve placement. Paravalvular aortic regurgitation has been associated with long-term mortality after transcatheter aortic valve replacement. Whether omitting preimplant balloon valvuloplasty affects paravalvular aortic regurgitation after Edwards Sapien transcatheter aortic valve replacement is currently unknown.
\end{abstract}

Methods: We retrospectively analyzed the clinical outcome of 121 consecutive patients undergoing transapical $(\mathrm{N}=50)$ or transfemoral $(\mathrm{N}=71)$ Edwards Sapien transcatheter aortic valve replacement. Routinely, no preimplant balloon valvuloplasty was performed in transapical procedure as opposed to uniform preimplant balloon valvuloplasty in transfemoral cases. The incidence and severity of total and paravalvular aortic regurgitation and 30-day clinical outcomes were compared between the 2 cohorts.

Results: The average patient's age was 84.4 years, with a higher prevalence of smoking history $(68 \%$ vs $42 \%, P=.005)$ and peripheral vascular disease $(38 \%$ vs $20 \%, P=.03)$ in the patients undergoing transapical replacement. The preprocedural transthoracic echocardiographic and computed tomography findings were similar between the 2 cohorts. After transcatheter aortic valve replacement, the incidence of mild to moderate total aortic regurgitation $(42 \%$ transfemoral vs 38\% transapical), paravalvular aortic regurgitation (39\% transfemoral vs $30 \%$ transapical), device success $(88.7 \%$ transfemoral vs $94.0 \%$ transapical), and 30-day composite end points (9.9\% transfemoral vs $14.0 \%$ transapical) were comparable in both groups. Multivariate regression analysis revealed male gender (odds ratio, 2.7; 95\% confidence interval, 1.18-6.35; $P=.02$ ) but not preimplant balloon valvuloplasty as an independent predictor for mild or greater total aortic regurgitation.

Conclusions: Compared with transapical transcatheter aortic valve replacement without preimplant balloon valvuloplasty, preimplant balloon valvuloplasty before transfemoral transcatheter aortic valve replacement resulted in a similar degree of prosthesis-related regurgitation, device success, and 30-day composite safety outcomes. (J Thorac Cardiovasc Surg 2015;150:1111-7)

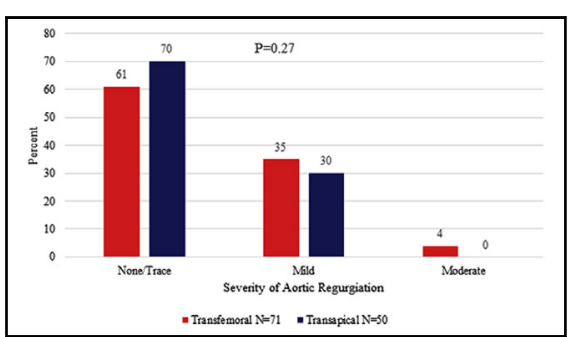

Paravalvular leak in TF with preimplant valvuloplasty versus TA without preimplant valvuloplasty.

\section{Central Message}

Omitting preimplant valvuloplasty in balloonexpandable TAVR has no impact on prosthesis-related regurgitation or 30-day outcomes.

\section{Perspective}

The impact of PBV on prosthesis-related regurgitation is unclear. This study showed a similar degree of paravalvular leak in patients after TA TAVR without PBV and after TF TAVR with PBV. Future studies comparing patients with and without PBV using the TF or TA approach are warranted.

See Editorial Commentary page 1118.

\footnotetext{
From the ${ }^{\mathrm{a}}$ Division of Cardiology, Department of Medicine, and Departments of

${ }^{\mathrm{b}}$ Anesthesiology and ${ }^{\mathrm{c}}$ Cardiothoracic Surgery, Weill Medical College of Cornell

University, New York, NY.

Received for publication March 19, 2015; revisions received June 29, 2015; accepted

for publication July 18, 2015; available ahead of print Aug 13, 2015.

Address for reprints: S. Chiu Wong, MD, Cardiac Catheterization Laboratories, Weill

Medical College of Cornell University, 520E 70th St, F433, New York, NY 10025

(E-mail: scwong@med.cornell.edu).

$0022-5223 / \$ 36.00$

Copyright (c) 2015 by The American Association for Thoracic Surgery

http://dx.doi.org/10.1016/j.jtcvs.2015.07.050
}

Aortic stenosis (AS) is the most common valve disorder in the elderly population in Western Europe and the United States. ${ }^{1,2}$ Once symptoms occur, AS is a highly lethal disease with an approximate $50 \%$ mortality rate in medically treated patients at 2 to 5 years depending on presenting symptoms. ${ }^{3}$ Approximately $30 \%$ to $50 \%$ of patients with AS have significant comorbidities and are deemed too high risk to undergo conventional surgical 


$$
\begin{aligned}
\text { Abbreviations and Acronyms } \\
\text { AR }=\text { aortic regurgitation } \\
\text { AS }=\text { aortic stenosis } \\
\text { CI }=\text { confidence interval } \\
\text { CT }=\text { computed tomography } \\
\text { OR }=\text { odds ratio } \\
\text { PBV }=\text { preimplant balloon valvuloplasty } \\
\text { PVAR }=\text { paravalvular aortic regurgitation } \\
\text { TA }=\text { transapical } \\
\text { TAVR }=\text { transcatheter aortic valve replacement } \\
\text { TF }=\text { transfemoral }
\end{aligned}
$$

aortic valve replacement procedures. ${ }^{1,4,5}$ Therefore, the recent approval of transcatheter aortic valve replacement (TAVR) has dramatically transformed the treatment approach for these high-risk patients.

Current procedural limitations that affect the short- and mid-term mortality in patients undergoing TAVR include vascular complications, cerebral embolic events, and paravalvular aortic regurgitation (PVAR) ${ }^{6-8}$ Previous studies using transcranial Doppler techniques have demonstrated that preimplant balloon valvuloplasty (PBV) may be associated with an increased risk of cerebral embolization. ${ }^{9,10}$ However, avoidance or elimination of PBV step in TAVR may result in less than optimal prosthetic valve expansion with a resultant increase in PVAR after TAVR, which has been associated with lower survival after both balloon-expandable and self-expanding stent valve systems. ${ }^{8,11}$ Furthermore, subsequent corrective attempts with postdilatation may result in a higher incidence of aortic annulus or root rupture or development of central valve regurgitation. Equally important, repeat dilation after prosthesis implantation has been associated with an increase in the incidence of periprocedural cerebral vascular events. ${ }^{12}$

Therefore, we sought to evaluate the procedural success and post-TAVR valve hemodynamics including central aortic regurgitation (AR) and PVAR in patients undergoing Edwards Lifesciences (Irvine, Calif) Sapien TAVR with a retrograde transfemoral (TF) approach with routine PBV versus patients undergoing an antegrade transapical (TA) approach without PVB. The secondary objectives were to compare the 30-day composite clinical safety end points, including all-cause and cardiac mortality, incidence of myocardial infarction, cerebral vascular events, and postTAVR hemodynamics, between the 2 treatment strategies.

\section{MATERIALS AND METHODS \\ Patient Population}

From May 1, 2012, to December 31, 2013, 121 consecutive high-risk or inoperable patients underwent Edwards Sapien TAVR for the treatment of symptomatic severe AS. All patients were evaluated and deemed appropriate candidates for TAVR procedure by at least 1 interventional cardiologist and 2 cardiothoracic surgeons. Patients who underwent TAVR for stenosis of a bioprosthetic valve and patients undergoing TA-TAVR as part of a clinical trial protocol that mandated preimplant valvuloplasty were excluded from the study. Food and Drug Administrationapproved Retroflex 3 or XT versions of the Edwards Sapien transcatheter heart valves were used in both TA and TF procedures. All patients underwent routine echocardiographic and computed tomography (CT) imaging to delineate aortic annular and iliac-femoral anatomies for valve sizing and access site assignment before procedures. The study protocol was approved by the institutional review board at the Weill Cornell Medical College, and all patients undergoing TAVR consented to be entered into an ongoing TAVR database of the William Acquavella Valve Center at the New York Presbyterian Hospital Center-Cornell Campus.

\section{Procedural Approaches}

Details of both TA and TF procedure steps have been reported. ${ }^{13,14}$ After general anesthesia, access sites for all patients undergoing the TF procedure were obtained percutaneously. If the entry site was deemed adequate by angiography, two 6F ProGlide devices (Abbott Vascular, Santa Clara, Calif) were used for preclosure followed by the placement of an appropriately sized Edwards delivery sheath. For both TF and TA cases, $7 \mathrm{~F}$ and $6 \mathrm{~F}$ sheaths were placed in the femoral artery and vein for pigtail and temporary pacemaker catheter placement for subsequent aortograms and rapid pacing during prosthesis implantation, respectively. For all patients undergoing the TA procedure, exposure of the heart was obtained using a standard rib retractor (State of the Art, Cedar Grove, $\mathrm{NJ}$ ). Concentric purse string sutures were placed in the myocardium lateral and superior to the true apex. An 18-gauge arterial needle was used for apical puncture through which a 0.035" Supra Core (Abbott Vascular) or Amplatz Super Stiff (Boston Scientific, Maple Grove, Minn) wire was then advanced across the aortic valve in an antegrade fashion into the descending aorta under fluoroscopic and transesophageal echocardiographic guidance. An appropriately sized dedicated Edwards delivery sheath was then placed over the $0.035^{\prime \prime}$ Supra Core or Amplatz Super Stiff wire into the left ventricle or femoral artery under fluoroscopic guidance for TA or TF procedures, respectively. After the placement of the Edwards delivery sheath, 3000 to 5000 units of intravenous unfractionated heparin were administered to achieve an activated clotting time of more than 250 seconds in all patients.

All patients receiving the TF procedure underwent routine PBV using the Z-Med II-X Balloon Dilatation Catheter (B Braun Interventional System Inc, Bethlehem, Pa) or the Edwards balloon catheter. No PBV was performed in the TA procedures. Rapid right ventricular pacing was performed during PBV, stent valve deployment, and TA access site closure. After prosthesis deployment, repeat balloon valvuloplasty with 0.5 to $2.0 \mathrm{~mL}$ of contrast added into the device delivery balloon was performed if more than mild PAVR was noted on transesophageal echocardiogram. Both the amount of additional contrast and the number of post-valve deployment balloon valvuloplasty attempts were left to the judgment of the implantation team.

After TF procedures, the described preclosure technique was used to optimize access site closure. ${ }^{15}$ For TA procedures, the sutures were secured and buttressed as needed. Intravenous protamine was administered after access site closure, and dual antiplatelet therapy of aspirin and clopidogrel was prescribed for 6 months after all procedures.

\section{In-Hospital and 30-Day Events}

All patients were monitored in the surgical intensive care unit postTAVR and evaluated daily by dedicated intensivists. After tracheal extubation, the patients remained in the intensive care unit for 1 to 2 days and transferred to the step-down unit for observation until discharge. Members of the heart team who participated in the preprocedural evaluation and TAVR implantation also assessed the patients daily during the entire 
hospital stay. All discharged patients returned for a 30-day office visit and were evaluated by an interventional cardiologist and a cardiothoracic surgeon.

\section{Definition of Terms}

For the current study, procedural complications included all-cause mortality, cardiac death, cerebral vascular event, myocardial infarction, acute kidney injury, access site-related complications, severity of central AR, and PVAR. The composite end points of device success and 30-day early safety were adjudicated according to the Valve Academic Consortium definitions. ${ }^{16,17}$ In addition, baseline moderate kidney dysfunction was defined as estimated glomerular filtration rate less than $60 \mathrm{~mL} / \mathrm{min} /$ $1.73 \mathrm{~m}^{2}$. CT-based cover index (\%) was used to assess congruence of area coverage between annulus and device and defined as $100 \times$ (stent valve diameter-annulus diameter derived from CT measured area)/stent valve diameter. ${ }^{18}$ Qualitative CT aortic valve calcium grade scale was defined as follows: grade $1=$ no calcification, grade $2=$ mild calcification with small isolated spots, grade $3=$ moderate calcification with multiple larger spots, and grade $4=$ heavy and extensive calcification of all cusps. ${ }^{19}$ Circularity of aortic annulus was assessed with the eccentricity index, using the formula $(1-$ minimal diameter/maximal diameter) with measurements of CT-based annular diameter at the basal aortic ring below the hinge point of the aortic valve cusps. ${ }^{20}$

\section{Statistical Analysis}

Continuous variables are presented as mean ( \pm standard deviation), and categoric variables are presented as frequencies (percentages). The normality of continuous variables was tested with the Shapiro-Wilk test, and the variables were compared by Student $t$ test or Mann-Whitney $U$ test as appropriate. Fisher exact test or Pearson's chi-square test was used to compare categoric variables. A stepwise backward multivariate logistic regression analysis was done to identify independent predictors of more than mild $\mathrm{AR}$ and device success by including all significant covariates. Common variables included in both univariate models included age, male gender, patient height, Society of Thoracic Surgeons score, peripheral vascular disease, left ventricular ejection fraction, preimplant valvuloplasty, number of postimplant dilatations, annulus eccentricity index, aortic valvular area index, qualitative aortic valve calcium grade, and cover index. In addition, body mass index and baseline estimated glomerular filtration rate were included in the mild or greater AR model, whereas porcelain aorta and prosthesis size were incorporated into the device success model. Significant covariates were identified using the aforementioned primary tests for categoric and continuous variables with a probability value of less than .15 except for the covariate TF PBV, which was forced into the multivariate regression model. Statistical significance was assumed when the null hypothesis could be rejected at $P$ less than .05 . All statistical analyses were performed using Stata software (version 13.0; StataCorp LP, College Station, Tex).

\section{RESULTS}

The 121 patients included in the study had a mean age of 84.4 years; 71 patients underwent a TF-TAVR with PBV, and 50 patients underwent TA-TAVR without PBV. Patients in the TA group had a higher prevalence of smoking history and peripheral vascular disease, whereas atrial fibrillation was marginally more frequent in the TF group (Table 1). On baseline transthoracic echocardiography, the severity of AS and the presence of mitral regurgitation were similar between the 2 groups. The degree of aortic valve calcification, annular diameter, and eccentricity index were comparable between the 2 groups; all 3 patients with porcelain aorta underwent the TA procedure (Table 2).
TABLE 1. Baseline patient demographics

\begin{tabular}{lccc}
\hline \multicolumn{1}{c}{ Characteristics } & TF $(\mathbf{N}=\mathbf{7 1})$ & TA $(\mathbf{N}=\mathbf{5 0})$ & $\begin{array}{c}\boldsymbol{P} \\
\text { Value }\end{array}$ \\
\hline Age (y) \pm SD & $84.4 \pm 7.5$ & $84.3 \pm 6.6$ & .92 \\
Female (\%) & $33(46)$ & $29(58)$ & .21 \\
Previous CABG (\%) & $15(21)$ & $17(34)$ & .12 \\
Hypertension (\%) & $59(83)$ & $44(88)$ & .46 \\
Smoking (\%) & $30(42)$ & $34(68)$ & .005 \\
Diabetes (\%) & $25(35)$ & $15(30)$ & .43 \\
BMI (kg/m $\left.{ }^{2}\right)$ & $27.4 \pm 6.7$ & $26.2 \pm 4.7$ & .28 \\
COPD (\%) & $21(30)$ & $16(32)$ & .78 \\
NYHA functional class N (\%) & & & .83 \\
$\quad$ Class I & $0(0)$ & $0(0)$ & \\
Class II & $23(32)$ & $15(20)$ & \\
Class III & $43(68)$ & $30(70)$ & \\
Class IV & $5(7)$ & $5(10)$ & \\
Moderate kidney dysfunction $(\%)$ & $37(52)$ & $31(62)$ & .28 \\
Renal dialysis (\%) & $3(4)$ & $3(6)$ & .66 \\
Peripheral vascular disease (\%) & $14(20)$ & $19(38)$ & .03 \\
Cerebral vascular accident (\%) & $9(13)$ & $10(20)$ & .28 \\
Atrial fibrillation (\%) & $33(46)$ & $15(31)$ & .07 \\
STS score & $8.5 \pm 4.6$ & $9.4 \pm 5.3$ & .33 \\
\hline BMI, Body ms
\end{tabular}

$B M I$, Body mass index; $C A B G$, coronary artery bypass grafting; $C O P D$, chronic obstructive pulmonary disease; $N Y H A$, New York Heart Association; $S D$, standard deviation; STS, Society of Thoracic Surgeons; $T A$, transapical; $T F$, transfemoral.

The advancement of prostheses across native valves was uniformly successful in all patients. All 29-mm valves were implanted in the patients in the TF group. The CT-based

TABLE 2. Preprocedural transthoracic echocardiographic and computed tomography findings

\begin{tabular}{|c|c|c|c|}
\hline $\begin{array}{c}\text { Transthoracic } \\
\text { echocardiographic variables }\end{array}$ & TF $(\mathbf{N}=71)$ & TA $(\mathbf{N}=\mathbf{5 0})$ & $\begin{array}{c}P \\
\text { value }\end{array}$ \\
\hline LVEF $(\%)$ & $49 \pm 15$ & $50 \pm 14$ & .78 \\
\hline Aortic valve area $\left(\mathrm{cm}^{2}\right)$ & $0.7 \pm 0.2$ & $0.7 \pm 0.2$ & .80 \\
\hline Peak velocity $(\mathrm{cm} / \mathrm{sec})$ & $4.6 \pm 0.6$ & $4.2 \pm 0.6$ & .50 \\
\hline Mean aortic gradient $(\mathrm{mm} \mathrm{Hg})$ & $51 \pm 14$ & $44 \pm 13$ & .14 \\
\hline AR & & & .06 \\
\hline None to trace $(\%)$ & $38(54)$ & $24(48)$ & \\
\hline Mild (\%) & $25(34)$ & $26(52)$ & \\
\hline Moderate $(\%)$ & $4(6)$ & $0(0)$ & \\
\hline Severe $(\%)$ & $4(6)$ & $0(0)$ & \\
\hline Mitral regurgitation & & & .66 \\
\hline None to trace $(\%)$ & $26(36)$ & $20(40)$ & \\
\hline Mild (\%) & $32(45)$ & $21(42)$ & \\
\hline Moderate $(\%)$ & $12(17)$ & $9(18)$ & \\
\hline Severe $(\%)$ & $2(2)$ & $0(0)$ & \\
\hline \multicolumn{4}{|l|}{$\mathrm{CT}$ anatomic variables } \\
\hline $\begin{array}{l}\text { Qualitative aortic valve } \\
\text { calcium grade }\end{array}$ & $2.4 \pm 1$ & $1.9 \pm 1.4$ & .07 \\
\hline $\begin{array}{l}\text { Annular average diameter } \\
\quad(\mathrm{mm}) \pm \mathrm{SD}\end{array}$ & $23.6 \pm 2.4$ & $22.8 \pm 2.3$ & .31 \\
\hline Eccentricity index & $0.21 \pm 0.08$ & $0.18 \pm 0.09$ & .41 \\
\hline Porcelain aorta $(\%)$ & $0(0)$ & $3(6)$ & .06 \\
\hline
\end{tabular}

$A R$, Aortic regurgitation; $C T$, computed tomography; $L V E F$, left ventricular ejection fraction; $S D$, standard deviation; $T A$, transapical; $T F$, transfemoral. 
TABLE 3. Procedural and predischarge echocardiographic findings

\begin{tabular}{|c|c|c|c|}
\hline Variable & TF $(N=71)$ & TA $(\mathbf{N}=50)$ & $\begin{array}{c}P \\
\text { value } \\
\end{array}$ \\
\hline Bioprosthesis diameter & & & .08 \\
\hline $23 \mathrm{~mm}(\%)$ & $33(46)$ & $23(46)$ & \\
\hline $26 \mathrm{~mm}(\%)$ & $28(39)$ & $27(54)$ & \\
\hline $29 \mathrm{~mm}(\%)$ & $10(14)$ & $0(0)$ & \\
\hline $\begin{array}{l}\text { Stent valve/mean annular } \\
\text { diameter ratio }\end{array}$ & $0.06 \pm 0.02$ & $0.07 \pm 0.02$ & .70 \\
\hline Cover index $(\%)$ & $3.7 \pm 7.3$ & $7.2 \pm 6$ & .14 \\
\hline Postimplant dilatations & & & .70 \\
\hline No & $47(67)$ & $35(70)$ & \\
\hline Yes & $24(33)$ & $15(30)$ & \\
\hline Aortic valve area $\left(\mathrm{cm}^{2}\right)$ & $1.6 \pm 0.3$ & $1.7 \pm 0.2$ & .23 \\
\hline Peak velocity $(\mathrm{cm} / \mathrm{sec})$ & $2.4 \pm 0.4$ & $2.2 \pm 0.4$ & .18 \\
\hline Mean aortic gradient (mm Hg) & $11.2 \pm 5.1$ & $10.4 \pm 5.7$ & .22 \\
\hline Mitral regurgitation & & & .11 \\
\hline None to trace $(\%)$ & $16(23)$ & $21(42)$ & \\
\hline Mild (\%) & $39(55)$ & $22(44)$ & \\
\hline Moderate $(\%)$ & $13(18)$ & $7(14)$ & \\
\hline Severe $(\%)$ & $2(3)$ & $0(0)$ & \\
\hline Total prosthesis-related AR & & & .32 \\
\hline None/trace & $41(58)$ & $31(62)$ & \\
\hline Mild & $27(38)$ & $19(38)$ & \\
\hline Moderate & $3(4)$ & $0(0)$ & \\
\hline PVAR & & & .27 \\
\hline None/trace & $44(62)$ & $35(70)$ & \\
\hline Mild & $24(34)$ & $15(30)$ & \\
\hline Moderate & $3(4)$ & $0(0)$ & \\
\hline Device success rate $(\%)$ & $88.7 \%$ & $94 \%$ & .32 \\
\hline
\end{tabular}

$A R$, Aortic regurgitation; $P V A R$, paravalvular aortic regurgitation; $T A$, transapical; $T F$, transfemoral.

cover index did not differ significantly between the 2 patient cohorts. After TAVR, $33 \%$ of TF and $37 \%$ of the TA cases required post-TAVR dilations $(P=.70)$. The overall severity of mitral regurgitation pre- and post-TAVR was comparable between the 2 treatment groups (Tables 2 and 3 ). At least mild total AR occurred in 49 patients (Figure 1). In the predischarge transthoracic echocardiogram, the degree of total $\mathrm{AR}$ and PVAR was comparable in both groups (Figure 1, $A$ and $B$ ). Moderate total or paravalvular AR was uncommon and occurred only in $3 \mathrm{TF}$ cases; no patient had severe AR. The post-TAVR valve area, transvalvular gradient, and device success rate were similar in both cohorts (Table 3).

Of the 3 patients who died in the TF group, 2 died of procedural, prosthesis-related complications (1 of severe PVAR leading to heart failure, and 1 of aortic rupture during initial valve deployment). Of the 4 patients who died in the TA group, 1 died of procedural, prosthesis-related complications (valve embolization during the procedure). No death was due to post-TAVR dilatation. Two patients in the TF group experienced cerebral vascular events less than 72 hours postprocedure. The patients in the TA group received more transfusions, despite a similar vascular complication rate. There was no difference in 30-day

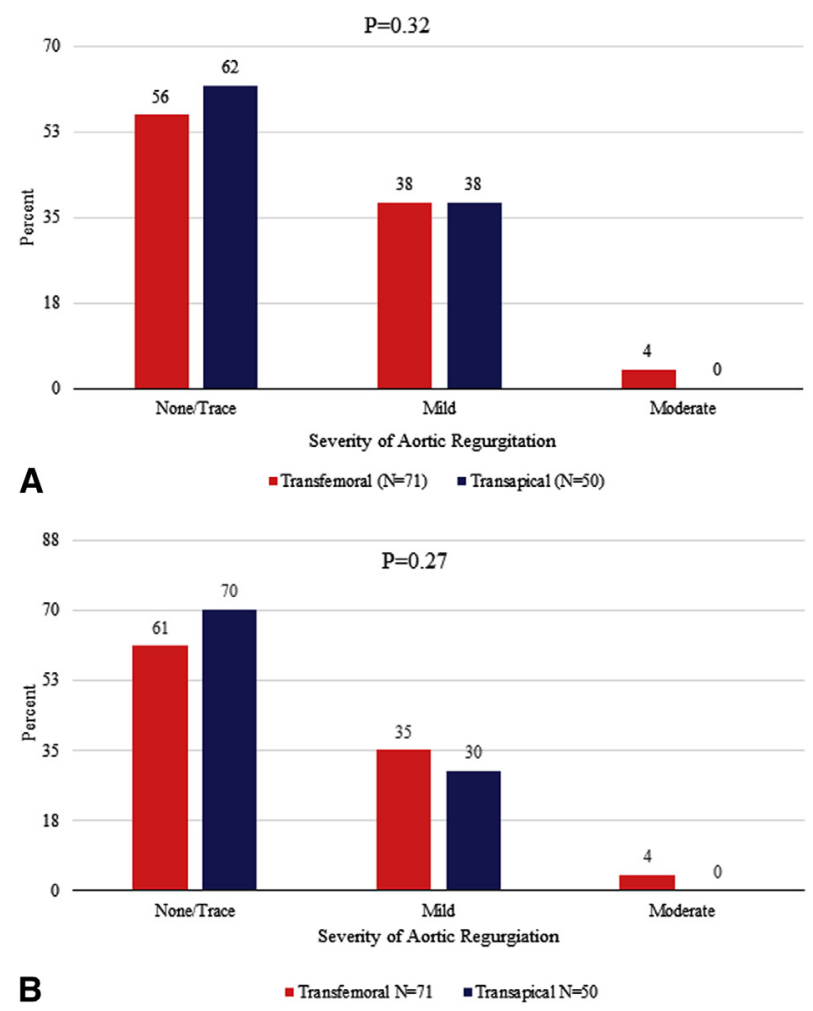

FIGURE 1. A, Total prosthesis-related AR. Total prosthesis AR was graded as none to trace in 41 patients, mild in 27 patients, and moderate in 3 patients who underwent the TF procedure compared with as none to trace in 31 patients, mild in 19 patients, and moderate in zero patients in the TA group on predischarge transthoracic echocardiograms. No patient experienced severe AR in either group $(P=.32)$. B, PVAR was graded as none to trace in 44 patients, mild in 24 patients, and moderate in 3 patients who underwent the TF procedure compared with none to trace in 35 patients, mild in 15 patients, and moderate in zero patients in the TA group on predischarge transthoracic echocardiograms. No patient experienced severe AR in either group $(P=.27)$.

mortality, stroke, or composite clinical safety end points in both treatment groups (Table 4). Multivariate analysis revealed male gender (odds ratio [OR], 2.7; 95\% confidence interval $[\mathrm{CI}], 1.18-6.35 ; P=.02$ ) and marginally, body mass index (OR, $0.92 ; 95 \% \mathrm{CI}, 0.85-1.00 ; P=.05$ ) as independent predictors for at least mild total AR post-TAVR. Of note, the weak trend toward a lower likelihood of at least mild total prosthesis AR after TF-TAVR with PVB versus TA-TAVR without PVB (OR, 0.73; 95\% CI, 0.32-1.70) did not approach statistical significance $(P=.47)$ in the present study population. Finally, no univariate or multivariate predictors for device success were identified.

\section{DISCUSSION}

Recent randomized clinical trials have demonstrated superior clinical outcomes in inoperable patients with severe AS who underwent TAVR compared with medical therapy ${ }^{21}$ and at least equivalent, ${ }^{22}$ if not superior, ${ }^{23}$ clinical 
TABLE 4. Thirty-day clinical outcomes

\begin{tabular}{lccc}
\hline \multicolumn{1}{c}{ Variable } & TF $(\mathbf{N}=\mathbf{7 1})$ & TA $(\mathbf{N}=\mathbf{5 0})$ & $\begin{array}{c}\boldsymbol{P} \\
\text { value }\end{array}$ \\
\hline All-cause mortality (\%) & $3(4)$ & $4(8)$ & .50 \\
Cardiac mortality (\%) & $3(4)$ & $3(6)$ & .74 \\
Stroke (\%) & $2(3)$ & $0(0)$ & .51 \\
MI (\%) & $0(0)$ & $0(0)$ & $\mathrm{n} / \mathrm{a}$ \\
New permanent pacemaker (\%) & $4(6)$ & $5(10)$ & .48 \\
Transfusion (\%) & $17(24)$ & $28(56)$ & $<.001$ \\
Bleeding complications (\%) & $2(3)$ & $4(8)$ & .23 \\
Vascular complications (\%) & $2(3)$ & $1(2)$ & 1.00 \\
Stage 2 AKI (\%) & $1(1)$ & $2(4)$ & .57 \\
Stage 3 AKI (\%) & $1(1)$ & $1(2)$ & .85 \\
Composite safety end points (\%) & $9.9 \%$ & $14 \%$ & .48 \\
\hline AKI Acto
\end{tabular}

$A K I$, Acute kidney injury; $M I$, myocardial infarction; $n / a$, not available; $T A$, transapical; $T F$, transfemoral

outcomes in high-risk patients compared with surgical aortic valve replacement. Our retrospective study showed that PBV may be safely omitted in TA-TAVR without adversely affecting the overall outcome of the procedure.

Current TAVR procedures are limited by a number of procedural and device-related complications, including a higher incidence of permanent pacemaker implantation after CoreValve (Medtronic Inc, Minneapolis, Minn) implantation, ${ }^{24,25}$ vascular complications (including aortic rupture, aorto-iliac-femoral dissection, and perforation), access site bleeding complications, cerebral vascular events, and central and PVAR. ${ }^{26}$

The prevalence of high-grade conduction abnormality requiring permanent pacemaker implantation is partly dictated by the stent valve construct, depth of stent valve implantation into the left ventricular outflow tract, and patient-related factors, such as preexisting bundle branch block, implant valve size to annular diameter ratio, degree of valve and left ventricular outflow tract calcification, and PBV. ${ }^{27,28}$

\section{Transcatheter Aortic Valve Replacement-Related Cerebral Vascular Events}

Cerebral vascular accident is considered one of the most feared complications associated with TAVR. Although the 30-day and 1-year major stroke rates were higher in the TAVR than in the surgically treated cohort in the Placement of Aortic Transcatheter Valve IA trial, the longer term, 36month follow-up demonstrated clinical equipoise in both cohorts. ${ }^{8}$ In a meta-analysis involving 10,037 patients, Eggebrecht and colleagues ${ }^{29}$ reported an overall stroke rate of $3.3 \% \pm 1.8 \%$, which carried a 3.5 -fold increase in 30-day mortality. It is important to closely consider all possible clinical and procedure-related factors that may contribute to debris embolization during the TAVR procedure. By using the Placement of Aortic Transcatheter Valve database, Miller and colleagues ${ }^{30}$ identified 2 distinct phases of neurologic events after TAVR: an early phase that peaked during the first week and a constant late phase lasting up to 2 years postprocedure. Patients who underwent TAVR had a higher rate of cerebral events than surgical patients during the early phase, especially in patients with a smaller aortic valve index. In the late phase, patients who were not TF candidates and those with a history of neurologic events and advanced functional disability had a higher incidence of cerebral events after Edward Sapien valve implantation. ${ }^{30}$ Furthermore, previous studies using intraoperative transcranial Doppler to monitor procedural cerebral embolization during the TAVR procedure documented a higher number of high-intensity transient signals during wire manipulation in the arch, PBV, prosthesis deployment, and postimplant dilations, all of which may contribute to subsequent cerebral vascular events. ${ }^{9,11,12}$ Therefore, if PBV can be omitted without compromising valve delivery, expansion, annular anchorage, apposition, or degree of prosthesisrelated AR, it may help enhance the procedural safety.

\section{Transcatheter Aortic Valve Replacement-Related Aortic Regurgitation}

Paravalvular and total AR have been associated with reduced survival after TAVR. ${ }^{11,19}$ Therefore, any procedural strategy that may result in an increase in postTAVR AR should be avoided. Willson and colleagues ${ }^{31}$ demonstrated the importance of using $\mathrm{CT}$ for more precise aortic annular sizing to reduce TAVR-related PAVR and total AR. Other procedural and anatomic factors associated with PAVR included device malposition in reference to the aortic annulus, inadequate expansion of the stent valve, severity of valve calcification, unfavorable stent to annulus ratio, presence of aortic annulus calcific nodule, cover index, annular eccentricity, and left ventricular outflow tract calcification. In our study, the incidences of these anatomic and procedure-related factors were similarly distributed between the 2 cohorts. Our data demonstrated that elimination of the PBV step during TA-TAVR did not influence the severity of PVAR or total AR, post-TAVR hemodynamics, valve area, or device success rate.

\section{Previous Studies on Direct Transcatheter Aortic Valve Replacement Without Preimplantation Balloon Valvuloplasty}

Grube and colleagues ${ }^{32}$ first reported the feasibility of direct retrograde TF CoreValve deployment in 60 consecutive patients without PBV in a multicenter registry and achieved similar valve area and hemodynamics, including PVAR and 30-day clinical outcomes compared with historical control. At 30 days, all-cause mortality and stroke/transient ischemic attack were $6.7 \%$ and $5.0 \%$, respectively, in the study group compared with $14.3 \%$ and $11.9 \%$, respectively, in the control cohort. Garcia and colleagues ${ }^{33}$ recently summarized their experience on 10 selected 
high-risk patients who were deemed "feasible" for direct TF Edward Sapien valve without PBV. All procedures were successful, and no postdilation was performed. Only 4 patients had trivial to mild AR, and 6 patients had none. All patients were event-free at 30 days. Two case reports have been published with the direct TA approach without PBV. Wendler and colleagues ${ }^{34}$ summarized 6 patients with the direct TA approach using Edwards Sapien XT valves and demonstrated a significant reduction in procedural time and amount of contrast used compared with patients with PBV. More recently, Conradi and colleagues ${ }^{35}$ reported on a retrospective study comparing 50 patients undergoing direct TA-TAVR with 50 patients with PBV before TA-TAVR with the Edwards Sapien XT valves. The overall valve hemodynamics, including PVAR, device success, and 30-day mortality and stroke rates, were similar between the 2 approaches. Likewise, our study demonstrated that it is both feasible and safe to eliminate the PBV step in patients undergoing TA Edwards Sapien Retroflex3 or XT heart valve placement. The acute improvements in valve area and transvalvular gradient were similar with either approach. The number of postdeployment balloon dilations was also comparable, indicating that the radial force achieved by expansion of the stent valve, with or without $\mathrm{PBV}$, is adequate to overcome the compressive constraints of the combined calcified complex of the periaortic annulus, aortic valve leaflets, and ventricular outflow tract. There was no difference in the degree of PAVR or total AR between the 2 cohorts. Of note, the Valve Academic Research Consortium-defined device success and the composite 30-day clinical end points were also similar in both patient cohorts. It is intriguing to note that both Conradi and colleagues ${ }^{35}$ and our current study, using the Valve Academic Research Consortium definitions, ${ }^{16,17}$ concordantly reported a $94 \%$ device success rate and a 14\% 30-day composite safety end points in 50 patients undergoing direct TA-TAVR with the Edwards Sapien heart valve.

\section{Study Limitations}

The current study summarized a single-center experience comparing procedural and clinical results after a retrograde TF approach with mandated PBV versus an antegrade TA approach without PBV. The similar procedural and outcomes in both strategies warrants confirmation by other centers. The lack of clinically evident cerebral vascular events between the 2 approaches is comforting; however, the true incidence of neurologic events is not precise, because a detailed neurologic examination was not obtained by a neurologist and the number of patients in each group is rather small to make a definitive claim. Indeed the lack of association of PBV with postimplant AR may be due to our study being underpowered to detect a difference. Because of the small sample size, it is possible all confounders were not adjusted for. Moreover, a mean device success rate of only $91 \%$ may have had an impact on regression analysis. Furthermore, PBV before TF or TA prosthesis deployment may result in different prosthesis and annulus interactions during heart valve deployment and potentially affects the incidence and severity of central and paravalvular AR. Therefore, the lack of difference in AR post-TAVR from our study may not be applicable to patients undergoing retrograde TF-TAVR without PBV. Furthermore, other intrinsic differences between $\mathrm{TF}$ and TA cases may have confounded the comparison between those undergoing and not undergoing PBV. Only a well-powered randomized study that directly compares a retrograde approach with and without PBV can truly evaluate the impact and necessity of PBV on device success and clinical outcomes in patients undergoing TF TAVR.

\section{CONCLUSIONS}

Our study demonstrated the feasibility of omitting the PBV step in patients undergoing TA-TAVR for treatment of native AS using the Edwards Sapien stent valve. Procedural and clinical results with this simplified approach compared favorably to those of patients who underwent routine PBV before TF-TAVR with no significant differences in device expansion, valve hemodynamics, incidence and severity of prosthesis-related AR, device success, and 30-day procedure safety outcomes.

\section{Conflict of Interest Statement}

S. Chiu Wong, Richard B. Devereux, and Arash Salemi serve as members of Speakers Bureau and/or Proctors for Edwards Lifesciences Corporation. All other authors have nothing to disclose with regard to commercial support.

\section{References}

1. Lung B, Baron G, Butchart EG, Delahaye F, Gohlke-Bärwolf C, Levang OW et al. A prospective survey of patients with valvular heart disease in Europe: the Euro Heart Survey on Valvular Heart Disease. Eur Heart J. 2003;24:1231-43.

2. Carabello BA. Clinical practice aortic stenosis. N Engl J Med. 2002;346:677-82.

3. Ross J Jr, Braunwald E. Aortic stenosis. Circulation. 1968;38(1 Suppl):61-7.

4. Bouma BJ, van den Brink RBA, van der Meulen JHP, Verheul HA, Cheriex EC, Hamer HP, et al. To operate or not on elderly patients with aortic stenosis: the decision and its consequences. Heart. 1999;82:143-8.

5. Charlson E, Legedza AT, Hamel MB. Decision-making and outcomes in severe symptomatic aortic stenosis. J Heart Valve Dis. 2006;15:312-21.

6. Généreux P, Webb JG, Svensson LG, Kodali SK, Satler LF, Fearon WF, et al. Vascular complications after transcatheter aortic valve replacement. Insights from the PARTNER (Placement of AoRTic TraNscathetER Valve) Trial. J Am Coll Cardiol. 2012;60:1043-52.

7. Szeto WY, Augoustides JG, Desai ND, Moeller P, McGarvey ML, Walsh E, et al. Cerebral embolic exposure during transfemoral and transapical transcatheter aortic valve replacement. J Card Surg. 2011;26:348-54.

8. Kodali SK, Williams MR, Smith CR, Svensson LG, Webb JG, Makkar RR, et al. Two-year outcomes after transcatheter or surgical aortic-valve replacement. $N$ Engl J Med. 2012;366:1686-95.

9. Kahlert P, Al-Rashid F, Dottger P, Mori K, Plicht B, Wendt D, et al. Cerebral embolization during transcatheter aortic valve implantation. A transcranial Doppler study. Circulation. 2012;126:1245-55.

10. Drews T, Pasic M, Buz S, Unbehaun A, Dreysse S, Kukucka M, et al. Transcranial Doppler sound detection of cerebral microembolism during transapical aortic valve implantation. Thorac Cardiovasc Surg. 2011;59:237-42. 
11. Van Belle E, Juthier F, Susen S, Vincentelli A, Iung B, Dallongeville J, et al. Postprocedural aortic regurgitation in balloon-expandable and self-expandable transcatheter aortic valve replacement procedures: analysis of predictors and impact on long-term mortality: Insights from the FRANCE2 registry. Circulation. 2014;129:1415-27.

12. Nombela-France L, Rodes-Cabau J, Delarochelliere R, Larose E, Doyle D, Villeneuve J, et al. Predictive factors, efficacy, and safety of balloon postdilation after transcatheter aortic valve implantation with a balloon-expandable valve. JACC Cardiovasc Interv. 2012;5:499-512.

13. Webb JG, Chandavimol M, Thompson CR, Ricci DR, Carere RG, Munt BI, et al. Percutaneous aortic valve implantation retrograde from the femoral artery. Circulation. 2006;113:842-50.

14. Walther T, Dewey T, Borger MA, Kempfert J, Linke A, Becht R, et al. Transapical aortic valve implantation: step by step. Ann Thorac Surg. 2009;87:276-83.

15. Griese DP, Reents W, Diegeler A, Kerber S, Babin-Ebell J. Simple, effective and safe vascular access site closure with the double-ProGlide preclose technique in 162 patients receiving transfemoral transcatheter aortic valve implantation. Catheter Cardiovasc Interv. 2013;82:E734-41.

16. Leon MB, Piazza N, Nikolsky E, Blackstone EH, Cutlip DE, Kappetein AP, et al. Standardized endpoint definitions for transcatheter aortic valve implantation clinical Trials. A consensus report from the valve academic research consortium. J Am Coll Cardiol. 2011;57:253-69.

17. Kappetein AP, Head SJ, Généreux P, Piazza N, van Mieghem NM, Blackstone EH, et al. Updated standardized endpoint definitions for transcatheter aortic valve implantation. The valve academic research consortium- 2 consensus document. J Am Coll Cardiol. 2012;60:1438-54.

18. Détaint D, Lepage L, Himbert D, Brochet E, Messika-Zeitoun D, Iung B, et al. Determinants of significant paravalvular regurgitation after transcatheter aortic valve implantation impact of device and annulus discongruence. JACC Cardiovasc Interv. 2009;2:821-7.

19. Leipsic J, Gurvitch R, Labounty TM, Min JK, Wood D, Johnson M, et al. Multidetector computed tomography in transcatheter aortic valve implantation. JACC Cardiovasc Imaging. 2011;4:416-29.

20. Wong DT, Bertaso AG, Liew GY, Thomson VS, Cunnington MS, Richardson JD, et al. Relationship of aortic annular eccentricity and paravalvular regurgitation post transcatheter aortic valve implantation with CoreValve. J Invasive Cardiol. 2013;25:190-5

21. Leon MB, Smith CR, Mack M, Miller DC, Moses JW, Svensson LG, et al. Transcatheter aortic-valve implantation for aortic stenosis in patients who cannot undergo surgery. $N$ Engl J Med. 2010;363:1597-607.

22. Craig CR, Leon MB, Mack MJ, Miller DC, Moses JW, Svensson LG, et al. Transcatheter versus surgical aortic-valve replacement in high-risk patients. $N$ Engl J Med. 2011;364:2187-98.

23. Adams DH, Popma JJ, Reardon MJ, Yakubov SJ, Coselli JS, Deeb GM, et al. Transcatheter aortic-valve replacement with a self-expanding prosthesis. N Engl J Med. 2014;370:1790-8.

24. Popma JJ, Adams DH, Reardon MJ, Yakubov SJ, Kleiman NS, Heimansohn D, et al. Transcatheter aortic valve replacement using a self-expanding bioprosthesis in patients with severe aortic stenosis at extreme risk for surgery. J Am Coll Car diol. 2014;63:1972-81.

25. Abdel-Wahab M, Mehilli J, Frerker C, Neumann FJ, Kurz T, Tölg R, et al. Comparison of balloon-expandable vs self-expandable valves in patients undergoing transcatheter aortic valve replacement. The CHOICE Randomized Clinical Trial. JAMA. 2014;311:1503-14.

26. Kapadia SR, Svensson LG, Roselli E, Schoenhagen P, Popovic Z, Alfirevic A, et al. Single center TAVR experience with a focus on the prevention and management of catastrophic complications. Catheter Cardiovasc Interv. 2014;84 834-42.

27. Khawaja MZ, Rajani R, Cook A, Khavandi A, Moynagh A, Chowdhary S, et al Permanent pacemaker insertion after CoreValve transcatheter aortic valve implantation: incidence and contributing factors (the UK CoreValve Collaborative). Circulation. 2011;123:951-60.

28. Fraccaro C, Buja G, Tarantini G, Gasparetto V, Leoni L, Razzolini R, et al Incidence, predictors, and outcome of conduction disorders after transcath eter self-expandable aortic valve implantation. Am J Cardiol. 2011;107: 747-54.

29. Eggebrecht H, Schmermund A, Voigtlander T, Kahlert P, Erbel R, Mehta RH Risk of stroke after transcatheter aortic valve implantation (TAVR): a metaanalysis of 10,037 published patients. EuroIntervention. 2012;8:129-38.

30. Miller DC, Blackstone EH, Mack MJ, Svensson LG, Kodali SK, Kapadia S, et al. Transcatheter (TAVR) versus surgical (AVR) aortic valve replacement: occurrence, hazard, risk factors, and consequences of neurologic events in the PARTNER trial. J Thorac Cardiovasc Surg. 2012;143:832-43.

31. Willson AB, Webb JG, Freeman M, Wood DA, Gurvitch R, Thompson CR, et al. Computed tomography-based sizing recommendations for transcatheter aortic valve replacement with balloon-expandable valves: comparison with transesophageal echocardiography and rationale for implementation in a prospective trial. J Cardiovasc Comput Tomogr. 2012;6:406-14.

32. Grube E, Naber C, Abizaid A, Sousa E, Mendiz O, Lemos P, et al. Feasibility of transcatheter aortic valve implantation without balloon pre-dilation. A pilot study. JACC Cardiovasc Interv. 2011;4:751-7.

33. Garcia E, Martin P, Hernandez R, Rodríguez V, Fernández A, Gama V, et al. Feasibility and safety of transfemoral implantation of Edwards SAPIEN XT prosthesis without balloon valvuloplasty in severe stenosis of native aortic valve. Catheter Cardiovasc Interv. 2014;83:791-5.

34. Wendler O, Dworakowski R, Monaghan M, MacCarthy PA. Direct transapical aortic valve implantation: a modified transcatheter approach avoiding balloon predilation. Eur J Cardiothorac Surg. 2012;42:734-6.

35. Conradi L, Seiffert M, Schirmer J, Koschyk D, Blankenberg S, Reichenspurner $\mathrm{H}$, et al. Transapical transcatheter aortic valve implantation without prior balloon aortic valvuloplasty: feasible and safe. Eur J Cardiothorac Surg. 2013;46:61-6.

Key Words: aortic stenosis, transcatheter aortic valve replacement, predilation, valvuloplasty 